\title{
Perbedaan Persepsi Antara Mahasiswa Senior Dan Junior Mengenai Profesi Akuntan Pada Program S-1 Reguler Fakultas Ekonomi Universitas Lancang Kuning
}

\author{
FAIZAH KAMILAH
}

\author{
Fakultas Ekonomi Universitas Lancang Kuning \\ Jln. Yos Sudarso KM 8 Rumbai \\ Email: faizahkamilah76@yahoo.com
}

\begin{abstract}
This Research aimed to see whether there are differences in perception between senior and junior students of the accounting profession in the $S-1$ Regular program. The results showed that the $S-1$ Regular program, senior students perceptions of the "accountant as a profession" is lower than the junior student perceptions. The results showed that the more senior they (the longer they follow accounting education), the more they do not like accounting and increasingly do not want a career and worked as an accountant.
\end{abstract}

Keywor ds: Professional responsibility. Integrity, objectivity, competence, confidentiality

Isu Good Corporate Governance di Indonesia saat ini masih hangat dibicarakan karena dianggap sebagai faktor yang akan dapat memulihkan kepercayaan investor terhadap Indonesia dan media menciptakan suasana bisnis yang sehat di Indonesia. Salah satu komponen dari Corporate Governance adalah adanya pelaporan keuangan yang memadai, sayangnya sistem pelaporan keuangan yang ada saat ini masih perlu ditingkatkan dan diperbaiki. Rendahnya kualitas laporan keuangan dapat disebabkan kurangnya persepsi positif dari akuntan di Indonesia.

Dalam Kode Etik Akuntan Indonesia disebutkan bahwa tujuan profesi akuntansi adalah memenuhi tanggung-jawabnya dengan standar profesionalisme tertinggi, mencapai tingkat kinerja tertinggi, dengan orientasi kepada kepentingan publik. Seorang akuntan haruslah merupakan seorang individu yang dengan jelas dapat diidentifikasikan oleh pemakai jasa Akuntan sebagai profesional di bidang akuntansi. Prinsip Ketujuh Kode Etik Akuntan Indonesia menyebutkan bahwa prinsip Profesionalisme berarti setiap anggota harus berperilaku yang konsisten dengan reputasi profesi yang baik dan menjauhi tindakan yang dapat mendiskreditkan profesi. Prinsip profesionalisme seorang akuntan akan terwujud dengan baik apabila akuntan tersebut merasa bahwa profesi akuntan adalah penting dan memiliki tanggung jawab yang besar dalam masyarakat. Dengan demikian akuntan tersebut berusaha menjalankan tugas dengan sebaik-baiknya dan menjaga nama baik profesinya. Karena itulah, salah satu hal penting yang perlu ditekankan dalam pendidikan akuntansi adalah bagaimana membentuk nilai-nilai dan persepsi positif mahasiswa terhadap profesi.

Penelitian mengenai persepsi mahasiswa terhadap profesi akuntan memang masih jarang dilakukan. Penelitian oleh Nelson (1991) mengukur persepsi umum mahasiswa akuntansi terhadap profesi akuntan dengan menggunakan kuesioner yang dinamakan Accounting Attitude Scale (AAS). Penelitian ini dilakukan di Universitas yang berlokasi di Amerika Serikat. Marriott dan Marriott (2003) menggunakan kuesioner sebagaimana digunakan oleh Nelson untuk melakukan pengujian yang sama pada Universitas di Inggris dan menemukan bahwa terjadi perubahan persepsi mahasiswa akuntansi dari sejak awal masa kuliah mereka sampai ke senior. Marriott dan Marriott (2003) menyebutkan bahwa pendidikan akuntansi justru menyebabkan 
menurunnya persepsi positif mahasiswa akuntansi terhadap profesi akuntan.

Penelitian ini dilakukan untuk meneliti persepsi mahasiswa di perguruan tinggi Indonesia terhadap profesi akuntan. Penelitian ini seperti halnya penelitian Marriott dan Marriott (2003) bermaksud melihat perbedaan persepsi antar mahasiswa junior dan mahasiswa senior.

Gaa and Thorne (2004) mengatakan bahwa pendidikan akuntansi selama ini memfokuskan pada dimensi pilihan kebijakan tetapi tidak memperhatikan nilai dan kredibilitas yang mempengaruhi pilihan tersebut. Kemudian Gaa dan Thorne menyebutkan bahwa pada dasarnya akuntan memilih tindakan berdasarkan nilai yang ada dalam pikiran mereka.

Nilai-nilai yang dianut oleh seorang akuntan tidak terlepas dari bagaimana dia memandang profesi akuntan itu sendiri, apakah ia akan memandang penting profesi akuntan dan dengan sendirinya memandang penting pekerjaan yang dilakukannya. Tentunya nilai-nilai ini juga akan dipengaruhi oleh hal-hal yang sifatnya individual, seperti karakteristik sosial dan pengalaman masa lalunya. Walaupun demikian, pada saat mahasiswa tersebut memilih jalur karirnya untuk menjadi seorang akuntan, mahasiswa tersebut telah memiliki pandangan mengenai akuntan sebagai sebuah profesi.

Menurut pengertian umum, seseorang dikatakan profesional jika memenuhi tiga kriteria, yaitu mempunyai keahlian untuk melaksanakan tugas sesuai dengan bidangnya, melaksanakan suatu tugas atau profesi dengan menetapkan standard baku di bidang profesi yang bersangkutan dan menjalankan tugas profesinya dengan mematuhi Etika Profesi yang telah ditetapkan. Profesi dan profesionalisme dapat dibedakan secara konseptual. Profesi merupakan jenis pekerjaan yang memenuhi beberapa kriteria, sedangkan profesionalisme adalah suatu atribut individul yang penting tanpa melihat suatu pekerjaan merupakan suatu profesi atau tidak (Lekatompessy, 2003 dalam Herawati dan Susanto, 2009:3).
Menurut Kamus Besar Bahasa Indonesia:Profesi adalah pekerjaan dimana dari pekerjaan tersebut diperoleh nafkah untuk hidup, sedangkan profesionalisme dapat diartikan bersifat profesi atau memiliki keahlian dan keterampilan karena pendidikan dan latihan (Badudu dan Sutan, 2002:848).

Secara sederhana, profesionalisme berarti bahwa auditor wajib melaksanakan tugas-tugasnya dengan kesungguhan dan kecermatan. Sebagai seorang yang professional, auditor harus menghindari kelalaian dan ketidakjujuran. Arens et al. (2003) dalam Noveria (2006:3) mendefinisikan profesionalisme sebagai tanggung jawab individu untuk berperilaku yang lebih baik dari sekedar mematuhi undang-undang dan peraturan masyarakat yang ada. Profesionalisme juga merupakan elemen dari motivasi yang memberikan sumbangan pada seseorang agar mempunyai kinerja tugas yang tinggi (Guntur dkk, 2002 dalam Ifada dan M. Ja'far, 2005:13). Sebagai profesional, auditor mengakui tanggung jawabnya terhadap masyarakat, terhadap klien, dan terhadap rekan seprofesi, termasuk untuk berperilaku yang terhormat, sekalipun ini merupakan pengorbanan pribadi.

\section{METODE}

Penelitian ini ditujukan untuk melihat persepsi mahasiswa akuntansi terhadap profesi akuntan. Persepsi mahasiswa ini diukur dengan menggunakan AccountantAttitude Scale (AAS) yang dikembangkan oleh Nelson (1991) sebagaimana digunakanoleh Marriott dan Marriott (2003).

Penelitian ini bermaksud melihat dan menganalisa persepsi mahasiswa akuntansi karenanya responden yang digunakan dalam penelitian ini adalah mahasiswa S1 Reguler Akuntansi, yang terbagi atas mahasiswa tingkat satu (junior) dan mahasiswa tingkat akhir (senior). Hal ini dimaksudkan untuk melihat efektivitas kurikulum akuntansi dalam membentuk 
persepsi mahasiswa terhadap profesi akuntan.

Accounting Attitude Scale (Nelson, 1991) terbagi menjadi 15 pertanyaaan menggunakan Likert Scale dengan skala 1 sampai 6. Skor 6 untuk pernyataan sangat setuju dan skor 1 untuk pernyataan sangat tidak setuju. Dalam melakukan interpretasi kuesioner.

Kelompok pertama adalah "akuntan sebagai karir" dan "akuntansi sebagai disiplin ilmu". Kelompok ini dapat dianggap sebagai intrinsic feelings. Kelompok berikutnya adalah "akuntansi sebagai profesi" yang dapat dikatakan sebagai extrinsicviews terhadap profesi akuntan. Kelompok ketiga adalah "akuntansi sebagai aktifitaskelompok" yang menunjukkan persepsi mahasiswa terhadap akuntansi sebagai suatu proses sosial.

Data hasil kuesioner dalam penelitian ini merupakan data ordinal karenanya pengujian yang digunakan adalah pengujian non parametrik. Perbandingan yang dilakukan adalah perbandingan antar dua kelompok sampel yang berbeda karenanya digunakan Uji Mann Whitney. Pengujian juga dilakukan untuk menguji validitas dan reliabilitas dari kuesioner dengan menggunakan cronbach alpha.

Dalam penelitian ini, dilakukan berbagai pengujian hipotesis. Pertama-tama, dilakukan pengujian untuk melihat ada tidaknya perbedaan persepsi antara mahasiswa junior dengan mahasiswa senior untuk menilai apakah proses pembelajaran yang dijalani oleh mahasiswa menyebabkan perubahan persepsi mahasiswa terhadap profesi akuntansi.

\section{$\mathrm{H}_{1}$ : Terdapat perbedaan persepsi mengenai} profesi akuntan antara mahasiswa junior dan mahasiswa senior.

Pendidikan akuntansi terbagi atas berbagai program studi, karenanya penelitian ini juga menguji apakah terdapat perbedaan persepsi antara mahasiswa yang terdapat dalam program-program studi tersebut.
$\mathrm{H}_{2}$ : Terdapat perbedaan persepsi mengenai profesi akuntan antara mahasiswa antar program studi yang berbeda.

\section{HASIL}

Sampel penelitian terdiri atas 120 mahasiswa dengan perincian sebagai berikut :

\begin{tabular}{|l|c|c|c|}
\hline Program & $\begin{array}{l}\text { Mhs } \\
\text { Senior }\end{array}$ & $\begin{array}{l}\text { Mhs } \\
\text { Awal }\end{array}$ & Total \\
\hline S1-Akuntansi & 80 & 40 & 120 \\
\hline Total Responden & 80 & 40 & 120 \\
\hline
\end{tabular}

\begin{tabular}{|c|c|c|}
\hline $\mathrm{No}$ & Pernyataan & S1 \\
\hline & AKUNTAN SEBAGAI KARIR : & \\
\hline 1 & Saya akan senang menjadi seorang akuntan. & 6.46 \\
\hline & $\begin{array}{l}\text { Akuntan hanya memperoleh sedikit kepuasan pribadi } \\
\text { dalam }\end{array}$ & \\
\hline 2 & Pekerjaannya & 5.99 \\
\hline \multirow[t]{3}{*}{3} & Akuntan adalah orang-orang yang membosankan & 6.99 \\
\hline & Rata-rata & 6.48 \\
\hline & AKUNTANSI SEBAGAI DISIPLIN ILMU: & \\
\hline 4 & Akuntansi menarik & 6.90 \\
\hline 5 & Saya suka akuntansi. & 6.88 \\
\hline 6 & Akuntansi hanyalah aktifitas mengingat aturan-aturan & 6.89 \\
\hline \multirow[t]{4}{*}{7} & $\begin{array}{l}\text { Dalam akuntansi banyak aturan yang bersifat tetap/kaku. } \\
\text { Tidak } \\
\text { memerlukan conceptual skills atau judgement } \\
\text { (penyesuaian) }\end{array}$ & 6.70 \\
\hline & Rata-rata & 6.80 \\
\hline & AKUNTAN SEBAGAI PROFESI: & \\
\hline & $\begin{array}{l}\text { Rekan saya berpendapat bahwa saya membuat keputusan } \\
\text { karir } \\
\text { yang baik jika saya menjadi akuntan. }\end{array}$ & 6.78 \\
\hline 9 & Keluarga saya senang jika saya menjadi akuntan. & 6.96 \\
\hline 10 & Profesi Akuntan sangat dihormati & 6.65 \\
\hline 11 & $\begin{array}{l}\text { Akuntan adalah sebuah profesi, setara dengan dokter dan } \\
\text { ahli } \\
\text { hukum. }\end{array}$ & 8.75 \\
\hline \multirow[t]{3}{*}{12} & Menjadi akuntan sangat bergengsi (prestise) & 6.65 \\
\hline & Rata-rata & 7.15 \\
\hline & AKUNTANSI SEBAGAI AKTIFITAS KELOMPOK & \\
\hline 13 & $\begin{array}{l}\text { Akuntan yang profesional, berinteraksi dengan banyak } \\
\text { orang. }\end{array}$ & 8.68 \\
\hline 14 & $\begin{array}{l}\text { Para akuntan sibuk dengan angka-angka, mereka jarang } \\
\text { bekerja } \\
\text { dengan orang lain* }\end{array}$ & 6.97 \\
\hline \multirow[t]{2}{*}{15} & $\begin{array}{l}\text { Akuntan lebih banyak bekerja sendiri dari pada bekerja } \\
\text { dengan } \\
\text { orang lain }\end{array}$ & 6.85 \\
\hline & Rata-rata & 7,50 \\
\hline
\end{tabular}




\section{PEMBAHASAN}

Pengujian dilakukan ketika ke-15 pernyataan tersebut dikelompokkan menjadi 4 kelompok besar. Untuk melihat perbedaan persepsi mahasiswa junior dengan mahasiswa senior dilakukan pengujian secara terpisah antara mahasiswa S-1 Reguler. Berikut hasil pengujiannya. Beda Mahasiswa Junior Dan Senior pada Program S-1 Reguler jika ke-15 pernyataan dikelompokkan menjadi 4 kelompok besar, hasil pengujiannya adalah sebagai berikut :.

\begin{tabular}{|l|r|c|c|}
\hline & $\begin{array}{c}\text { Mahasis } \\
\text { wa }\end{array}$ & Mahasiswa & Asymp. Sig. (2- \\
Senio & Junior & tailed) \\
\hline Akuntan sebagai karir & 16.4378 & 21.4367 & 0.077 \\
\hline Akuntansi sebagai ilmu & 24.7659 & 24.5437 & 0.229 \\
\hline Akuntan sebagai profesi & 33.4325 & 33.9327 & 0.031 \\
\hline $\begin{array}{l}\text { Akuntansi sebagai aktifitas } \\
\text { kelp }\end{array}$ & 23.8712 & 16.5679 & 0.015 \\
\hline
\end{tabular}

Dari pengujian diatas tampak bahwa yang signifikan berbeda adalah kelompok pernyataan mengenai akuntan sebagai profesi dan akuntansi sebagai aktifitas kelompok. Untuk pernyataan mengenai akuntan sebagai suatu profesi, skor mahasiswa senior lebih rendah daripada skor mahasiswa junior yang artinya persepsi mahasiswa junior mengenai profesi akuntan lebih positif daripada mahasiswa senior. Namun untuk pernyataan mengenai akuntansi sebagai aktifitas kelompok, hasilnya menunjukkan bahwa mahasiswa senior memiliki persepsi yang lebih baik daripada persepsi mahasiswa junior. Hal ini menunjukkan bahwa sejalan dengan proses pendidikan yang telah dijalani mahasiswa senior, mereka mendapat gambaran tentang ruang lingkup pekerjaan akuntan yang lebih luas dimana akuntansi adalah juga merupakan aktifitas kelompok.

Mahasiswa junior juga beranggapan bahwa akuntansi lebih menarik, profesi akuntan sangat dihormati. Mahasiswa junior senang akan menjadi akuntan dibandingkan dengan mahasiswa senior. Berdasarkan hasil tersebut dapat terlihat bahwa dengan semakin mempelajari akuntansi, mahasiswa S-1 senior semakin tidak suka akuntansi, akuntansi menjadi kurang menarik, mereka merasa bahwa profesi akuntan kurang dihormati.
Mereka tidak terlalu senang akan menjadi seorang akuntan dibandingkan dengan mahasiswa junior.

Dapat ditarik kesimpulan bahwa proses pengajaran telah berhasil memberi pemahaman yang lebih baik kepada mahasiswa senior mengenai akuntansi sebagai aktifitas kelompok, tapi belum berhasil meningkatkan persepsi mahasiswa senior mengenai akuntan sebagai sebuah profesi yang setara dengan dokter dan ahli hukum.

Oleh karena itu, kurikulum dan proses pengajaran pada program S-1 perlu ditingkatkan untuk menarik minat mahasiswa belajar akuntansi dan meningkatkan persepsi mereka mengenai profesi akuntan. Perlu diterapkan berbagai metode pengajaran agar semakin belajar akuntansi, mahasiswa menjadi semakin senang dengan akuntansi dan semakin ingin menjadi akuntan.

Penelitian ini juga membuktikan bahwa pada program S-1, mahasiswa senior memiliki persepsi yang lebih rendah dibandingkan dengan mahasiswa junior mengenai akuntan sebagai profesi. Berdasarkan hasil tersebut maka seharusnya dalam kurikulum S1 dimasukkan materi ajaran yang lebih mendorong extrinsic feelings mahasiswaterhadap profesi akuntan.

Namun kebalikannya, mahasiswa senior memiliki persepsi yang lebih tinggi dibandingkan dengan mahasiswa junior mengenai akuntan sebagai aktifitas kelompok. Dapat ditarik kesimpulan bahwa proses pengajaran di $\mathrm{S} 1$ telah berhasil memberi pemahaman yang lebih baik kepada mahasiswa bahwa akuntan memerlukan interaksi dengan lingkungannya. Oleh karena itu, kurikulum dan proses pengajaran pada program S-1 perlu ditingkatkan untuk meningkatkan minat mahasiswa dalam mempelajari akuntansi dan meningkatkan persepsi mereka mengenai profesi akuntan.

$$
\text { Sebagaimana dijelaskan oleh }
$$

(Waldelmi, 2016) bahwa efektifitas penyeleseian tugas akhir mahasiswa pada 
fakultas ekonomi prodi Akuntasnsi Universitas lancang kuning Baik

Hal ini menunjukkan bahwa kurikulum akuntansi S-1 saat ini masih perlu diperbaiki. Perlu dikaji berbagai metode pengajaran untuk meningkatkan persepsi mahasiswa mengenai profesi akuntan. Perlu diteliti lebih lanjut, apakah mahasiswa S1 merasa merasa bosan dengan pendekatan yang selama ini lebih banyak menekankan pada aspek konseptual. Jika persepsi mahasiswa mengenai profesi akuntan semakin rendah, dapat diartikan bahwa minat mahasiswa untuk menjadi akuntan semakin rendah, maka dikhawatirkan kualitas akuntan dimasa mendatang akan turun, karena mereka yang pintar-pintar tidak lagi berminat menjadi akuntan.

\section{SIMPULAN}

Penelitian ini juga membuktikan bahwa pada program $\mathrm{S}-1$, mahasiswa senior memiliki persepsi yang lebih rendah dibandingkan dengan mahasiswa junior mengenai akuntan sebagai profesi. Berdasarkan hasil tersebut maka seharusnya dalam kurikulum S1 dimasukkan materi ajaran yang lebih mendorong extrinsic feelings mahasiswaterhadap profesi akuntan. Namun kebalikannya, mahasiswa senior memiliki persepsi yang lebih tinggi dibandingkan dengan mahasiswa junior mengenai akuntan sebagai aktifitas kelompok. Dapat ditarik kesimpulan bahwa proses pengajaran di $\mathrm{S} 1$ telah berhasil memberi pemahaman yang lebih baik kepada mahasiswa bahwa akuntan memerlukan interaksi dengan lingkungannya. Oleh karena itu, kurikulum dan proses pengajaran pada program S-1 perlu ditingkatkan untuk meningkatkan minat mahasiswa dalam mempelajari akuntansi dan meningkatkan persepsi mereka mengenai profesi akuntan.

\section{DAFTAR RUJUKAN}

Badudu dan Sutan. (2002). Kamus Umum Bahasa Indonesia. Jakarta: Pustaka Sinar Harapan.
Herawati dan Susanto. (2009). Pengaruh Profesionalisme, Pengetahuan Mendeteksi Kekeliruan dan Etika Profesi terhadap Pertimbangan Tingkat Materialitas Akuntan Publik. Jurnal Akuntansi dan Keuangan Vol.11 No. 1

Ifada dan M. Ja'far. (2005). Pengaruh Sikap Profesionalisme Internal Auditor terhadap Peranan Internal Auditor dalam Pengungkapan Temuan Audit.Jurnal Bisnis, Manajemen dan Ekonomi. Vol.7 No. 3

Ikatan Akuntan Indonesia. (2006).

Standar Profesional Akuntan Publik. Yogyakarta: STIE YKPN

Mulyadi. (2002). Auditing. Jakarta: Salemba Empat.

Noveria. (2006). Pengaruh Profesionalisme Auditor Internal terhadap Work Outcome Audior Internal. Skripsi.. UNPAD Bandung

Sugiyono. (2007). Statistik Untuk

Penelitian. Bandung: CV Alfabeta

Sumarni dan Wahyuni. (2006). Metodologi Penelitian Bisnis. Yogyakarta: Andi Offset

Waldelmi, I. (2016) 'Analisis Efektifitas Penyelesaian Tugas Akhir Mahasiswa (Studi pada Fakultas Ekonomi Universitas Lancang Kuning Pekanbaru)'. pekanbaru: jurnal daya saing, pp. 183-185.

Wahyudi dan Aida. (2006), Profesionalisme Akuntan dan Proses PendidikanAkuntansi di Indonesia. Pustaka LP3ES Jakarta 